\title{
Sequential contralateral injection through the same transradial vascular approach in a chronic total occlusion
}

\author{
Maria C. Ferrer-Gracia, Jose A. Linares, Jose R. Ruiz
}

HCU Lozano Blesa, Zaragoza, Spain

Postep Kardiol Inter 2015; 11, 2 (40): 152-153

DOI: $10.5114 /$ pwki.2015.52291

Contralateral injection has been described as a useful tool in the treatment of chronic total occlusions (CTOs) to evaluate the distal segments of the occluded artery [1, 2].

This case shows that contralateral injections are feasible through just one puncture using a $6 \mathrm{Fr}$ sheath, a long guidewire of 0.014" and a 5 Fr diagnosis catheter in parallel.

We present a 64-year-old man with severe peripheral vasculopathy. Coronary angiography showed a chronic total occlusion at the left circumflex artery and severe stenosis in the right coronary artery; circulation to the marginal branch was supplied from a posterolateral branch of the right coronary artery.

Percutaneous coronaty intervention $(\mathrm{PCl})$ was performed through a $6 \mathrm{Fr}$ sheath placed in the right radial artery. We began the procedure treating the left circumflex artery occlusion with an EBU $3.56 \mathrm{Fr}$ guiding catheter and an Asahi Sion "J" guidewire which crossed the occlusion easily. However, after dilatations with a $2.5 \times 15 \mathrm{~mm}$ balloon, no distal filling was observed (Figure $1 \mathrm{~A}$ ).

We changed the first angioplasty guidewire for a 0.014" $300 \mathrm{~cm}$ length BMW guidewire. We passed in parallel a regular wire $(0.035$ " $260 \mathrm{~cm} \mathrm{~J})$ inside the guide catheter until it reached the aortic root. Then, using the same sheath, we changed to a JR 5 Fr diagnosis catheter to perform a contralateral injection. The injection from the right coronary artery showed that the guidewire was placed successfully in the marginal branch (Figure $1 \mathrm{~B}$ ). After that we advanced the previous guiding catheter using again the regular guide in the aortic root while still maintaining the 0.014 " BMW $300 \mathrm{~cm}$ in the marginal branch.

Needing buddy-wire technique, a $2.5 \times 33 \mathrm{~mm}$ everolimus drug-eluting stent was successfully deployed in the middle segment of the circumflex artery towards the marginal branch, and another similar $2.25 \times 18 \mathrm{~mm}$ stent distally to the previous one (Figure $1 \mathrm{C}$ ). Thereafter the collateral circulation to the marginal branch disappeared.

This case shows that contralateral injections are feasible through a unique puncture site using a $6 \mathrm{Fr}$ sheath, a long guidewire of 0.014 " placed in the endpoint branch and a $5 \mathrm{Fr}$ diagnosis catheter in parallel. The 0.035" $260 \mathrm{~cm} J$ regular wire placed in the aortic root helps to change catheters, improving the softness of the angioplasty guidewire (and avoiding its prolapse in the coronary artery).

Recently there have been published reports of two different ways to perform bilateral angiography in a single radial access once the wires had crossed the СTO but it was uncertain whether the wires were in the true lumen. The first one, called BASIRALA (bilateral angiography in a single radial access) [3], uses a microcatheter to inject selectively in the donor branches connected with CTOs. The second one [4] involves injecting with the same multipurpose guiding catheter in which the operator creates a loop of the wire in the coronary sinus and ascending aorta. This looped wire allows the catheter to be turned towards the contralateral artery without disengagement of the wire.

None of these three techniques can offer a real simultaneous contralateral injection.

It is possible, simple and safe to perform contralateral injections using a parallel long angioplasty 0.014" guidewire and a diagnosis catheter one French smaller than the sheath. The use of one $0.035 " 260 \mathrm{~cm}$ regular wire helps during catheter exchanges.

\section{Conflict of interest}

The authors declare no conflict of interest.

\section{Corresponding author:}

Maria Cruz Ferrer-Gracia, HCU Lozano Blesa, Avda. San Juan Bosco, 15, 50009 Zaragoza, Spain, phone: +34976556400,

e-mail: mcferrer10@gmail.com

Received: 10.12.2014, accepted: 16.03.2015. 

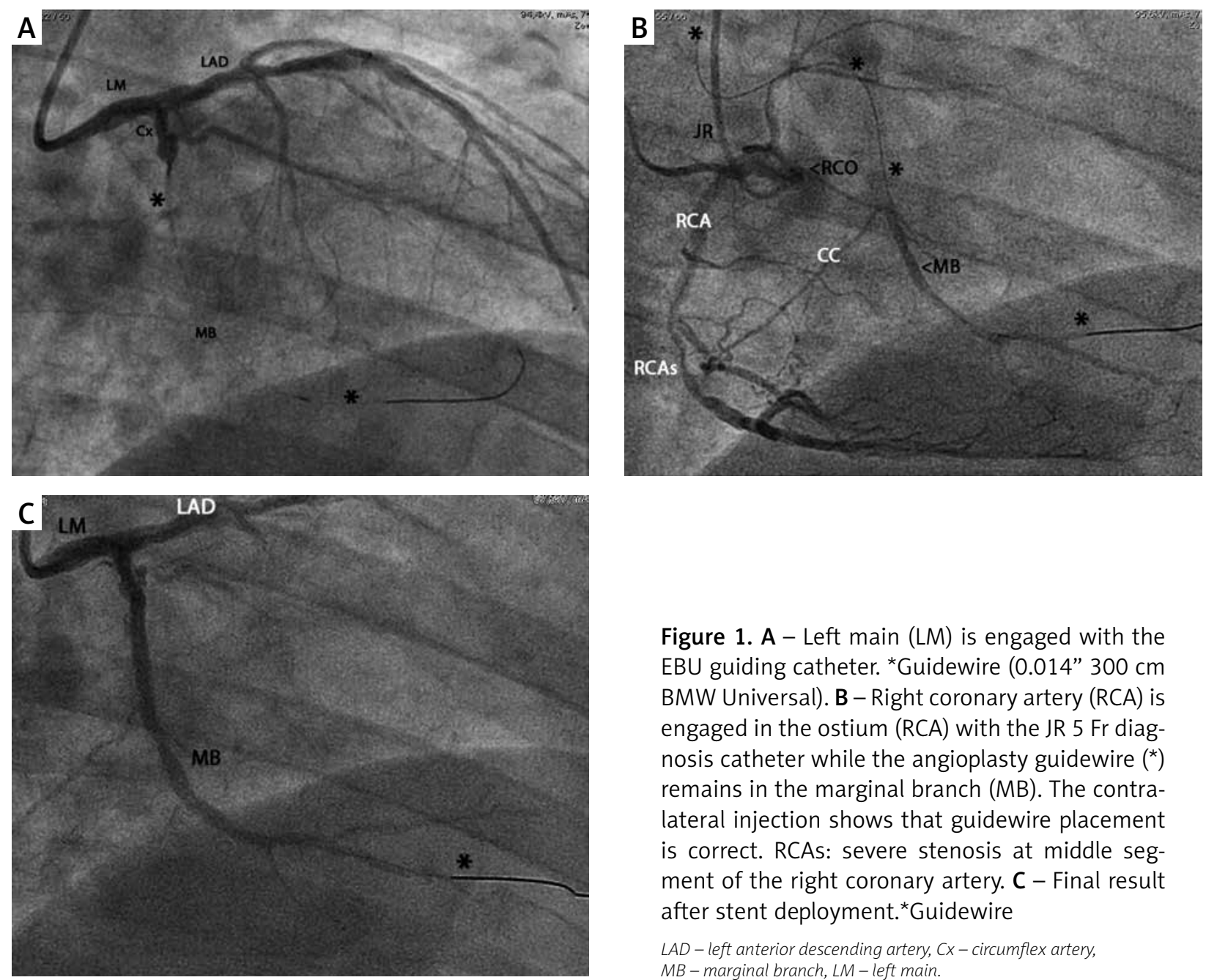

Figure 1. A - Left main (LM) is engaged with the EBU guiding catheter. *Guidewire $(0.014$ " $300 \mathrm{~cm}$ BMW Universal). B - Right coronary artery (RCA) is engaged in the ostium (RCA) with the JR 5 Fr diagnosis catheter while the angioplasty guidewire $\left(^{*}\right)$ remains in the marginal branch (MB). The contralateral injection shows that guidewire placement is correct. RCAs: severe stenosis at middle segment of the right coronary artery. C - Final result after stent deployment. ${ }^{\star}$ Guidewire

$\angle A D$ - left anterior descending artery, $C x$-circumflex artery, $M B$ - marginal branch, $L M$ - left main.

\section{References}

1. Singh M, Bell MR, Berger PB, et al. Utility of bilateral coronary injections during complex coronary angioplasty. J Invasive Cardiol 1999; 11: 70-4.

2. Weisz G, Moses JW. Contemporary principles of coronary chronic total occlusion recanalization. Catheter Cardiovasc Interv 2010; 75 Suppl 1: S21-7.

3. Zhang B, Wang F, Liao HT, et al. A new technique for bilateral angiography in a single radial access. Zhonghua Xin Xue Guan Bing Za Zhi 2013; 41: 108-10.

4. Kiemeneij F. Simultaneous transradial coronary angioplasty and contralateral coronary angiography with a single guide catheter for total coronary occlusions. J Invasive Cardiol 2014; 26: 87-90. 